\title{
BIOGEODYNAMICS IN TROPICAL AND BOREAL FORESTS
}

\author{
B.I.Kronberg ${ }^{1}$
}

\section{ABSTRACT}

Biogeodynamical interactions in tropical and boreal forest ecosystems are important regionally and globally. These ecosystems form the major continental carbon pools, and processes within these biomes control carbon dioxide flux rates between the continents and the atmosphere. Continued ecodynamic disruptions in these forests regions may perturb regional and possibly global carbon, energy and hydrosphere interactions.

\section{INTRODUCTION}

The tropical and boreal forests are the most extensive continental biomes. It is estimated that together these predominantly evergreen forests cover at least $10 \times 10^{6} \mathrm{~km}^{2}$ of closed high forests and an equal amount of open woodland and modified forests (BRUENIG, 1987). In addition to being major continental carbon reservoirs, these ecosystems influence hydrosphere-atmosphere exchanges on regional and global scales.

Boreal and tropical forests evolved on geological timescales under very different conditions. The boreal forests were repeatedly devastated during the Pleistocene glacial activity, while the impact of Quaternary climate changes on tropical forests is less certain. Most tropical forests overlie highly weathered terranes which have not been renewed for millions of years, and therefore have very low soil nutrient reserves. The overriding influence of nutrient scarcity in lowland tropical forest ecosystems is reflected in the mechanisms for recycling nutrients within the biomass. For boreal forests it appears that

\footnotetext{
'Geology Department, Lakehead University, Thunder Bay, Canada P7B 5E1.
} 
temperature is the most important variable controlling nutrient flow and hence the rate of biological activity.

Because boreal and tropical forests are important participants in the global carbon and water cycles, large-scale disruption of these ecosystems may have both regional and global effects. The eventual consequence of extensive clearing in rainforested regions, such as Amazonia, could be disruption of regional hydrologic cycles, and perhaps global energy exchanges. Changes in photosynthesis and respiration rates in the boreal forest may be contributing to the amplitude increases in the annual oscillation in the concentration curve of atmospheric carbon dioxide.

The unprecedented scale of disruption of natural processes in the boreal and tropical forests may perturb irreversibly regional and global carbon exchanges between the continents and the atmosphere. Quantifying forest-climate interactions remains a major challenge in modelling the linkages between global climate and the global carbon cycle.

\section{ENERGY AND HYDROLOGIC CYCLES IN TROPICAL AND BOREAL FORESTS}

Forests are biologically complex, dynamic interfaces between the ground and the atmosphere. The boreal forests and especially the tropical forests are important participants in regional hydrologic cycles and possibly the global energy cycle. For example, in forested tropical regions (latitudes between $12^{\circ} \mathrm{N}$ and $10^{\circ} \mathrm{S}$ ) large quantities of latent heat are produced as water is vaporized mainly from leaf sufaces. This heat is subsequently released to the atmosphere during cloud formation. At low latitudes latent heat is the largest contribution to atmospheric heating and is derived largely from air masses rising over South America, Africa and the major islands in the Far East (Indonesia, Phillipines, etc.) (NEWEL, 1971). Furthermore, tropical regions provide most of the sensible heat (i.e., heat exchanged as air passes over the Earth's surface) that is transported poleward to balance the negative radiation losses at higher latitudes (MOLION \& BETANCURT, 1981).

Studies show that exchanging forest for other land covers (cultivated plants, pasture, bare soil) perturbs both the sensible and latent heat fluxes to the atmosphere. After deforestation much more direct radiation is reflected (i.e., albedo is increased) and much less energy is available for transpiration and evaporation of intercepted rain. It is estimated that latent heat fluxes from bare soils are typically less than half those from forest (MOLION \& BETANCURT, 1981). These energy considerations can be used to speculate on the effects of forest clearing on the hydrologic cycle.

The major processes involved in the hydrologic cycle are those associated with runoff, precipitation and evapotranspiration. Over the long-term (e.g., annually), the net import of water vapor into the air column (evapotranspiration - precipitation) must be balanced by total runoff. The linkage between the energy and hydrologic cycles is especially strong in regions covered by tropical forests due to their large 
latent heat contributions to the atmosphere. In Amazonia, for example, the forests evapotranspire $\sim 50 \%$ of rain reaching the forest canopy (SALATI \& VOSE, 1984). Evapotranspiration typically has three components: transpiration by plants, soil moisture evaporation and evaporation of rainfall intercepted by forest cover (the latter component refers to rains which returns to the atmosphere as water vapor, without reaching the forest floor).

Futhermore, forest floors have a high capacity for water retention which will be profoundly altered by forest removal. Measurements by Schubart (personal communication) in Manaus demonstrate a 10 fold decrease in soil permeability 5 years after converting forested land to pasture. Furthermore, in the deforested areas the upper soil layer had been eroded by $10 \mathrm{~cm}$ (the natural rate of soil formation is $\sim 3 \mathrm{~cm}$ per century). There is abundant evidence that cultivating forested lands greatly increases (10-100 fold) soil erosion (BROWN \& WOLF, 1984).

In boreal ecosystems describing energy and hydrological factors is furthemore complicated by the incorporation of snow and frost dynamics into the study of long-term (e.g., annual) processes (PERSSON, 1980).

\section{PARTICIPATION OF BOREAL AND TROPICAL FORESTS IN THE GLOBAL CARBON CYCLE}

Forests cover one-third of the area of global land surfaces and comprise two-thirds of the total terrestrial carbon pool (REICHLE, 1975). The amount of carbon stored in global forests $\left(\sim 750 \times 10^{9}\right.$ tons) is estimated to be about the same as that held in the atmosphere (HOUGHTON \& WOODWELL, 1989). The amounts of carbon contained in soil is less certain but is believed to be approximately twice that held in forests. Carbon is removed from the atmosphere and fixed in land plants by photosynthesis at an estimated rate of $\sim 100 \times 10^{9}$ tons $\mathrm{C} / \mathrm{yr}(\sim 14 \%$ of total atmospheric carbon content). Carbon is returned to the atmosphere at approximately the same rate by respiration of plants and oxidation of organic matter.

The most direct evidence for the influence of forests on the global carbon cycle is the observed annual sinusoidal oscillation in the concentration curve of atmosphere carbon dioxide, which is much more pronounced in northern hemisphere measurements, than in those from southern hemisphere stations. These oscillations are attributed to the annual cycle of metabolism in seasonal forests. In the spring and summer the dominance of photosynthesis is reflected in the downward swing of the oscillation. The atmospheric carbon dioxide concentration increases again in fall and winter when respiration dominates. The influence of seasonal dynamics in forests on atmospheric carbon dioxide levels in underscored by the rapid (<1 month) response in atmospheric contents of carbon dioxide (MOORE \& BOLIN, 1987). The impact of the boreal forests is further emphasized by the much greater amplitude $(8 \mathrm{ppm})$ observed at Point Barrow $\left(71^{\circ} \mathrm{N}\right)$ over that $(3 \mathrm{ppm})$ observed at Mauna Loa $\left(20^{\circ} \mathrm{N}\right)$ (D'ARRIGO et al., 1987). Throughout the 
present decade a consistent year by year increase in amplitude has been measured (WOODWELL, 1987), and presumably is caused by changes in rates of photosynthesis and respiration in the seasonal northern temperature and boreal forest. To describe the factors affecting this signal apparently due to forestatmosphere interaction requires more detailed knowledge of how terrestrial ecosystems respond to environmental changes.

The size of the soil carbon pool in tropical and boreal forest is uncertain, as are the flux rates of carbon into and out of this dominant terrestrial carbon pool. Soil carbon content appear to decrease significantly with increases in the ratio of temperature to precipitation (BROWN \& LUGO, 1982). These factors would account for the smaller amounts of carbon stored in tropical forest soils than in those of boreal forests. There is also uncertainty regarding the amount of "soil" carbon stored in peatlands, common in boreal regions. Difficulties arise in incorporating peatlands into carbon cycle models because they represent a transition between biospheric and lithospheric (e.g., lignite, coal) carbon pools. An example of the problems which arise is given by TARNOCAl's (1972); he found $\sim 80 \%$ of soil carbon located in permafrost layers in some Canadian spruce forests. In boreal regions the flux rates of carbon dioxide to the atmosphere from deep detritus of forest floors may be controlled by physical processes (e.g., diffusion) rather than biochemical ones. For example, studies in northern forests show that carbon dioxide contents of soil air increase with depth and carbon dioxide concentrations as high as $15 \%$ in soil air have been documented (REINERS, 1975).

\section{NUTRIENT DYNAMICS AND SOIL FERTILITY IN TROPICAL AND BOREAL FORESTS}

Soil fertility is controlled by regional geologic history - in particular the time elapsed since the last regional renewal of land surfaces with rock debris (volcanic, glacial or alluvial) containing primary rock-forming minerals, which are the source of $\sim 30$ major and minor nutrient elements (FYFE et al., 1983). During weathering and soil formation, rock-derived nutrient elements (potassium, calcium, magnesium, phosphorus, zinc, etc.) are released as rock forming minerals (mainly feldspars) undergo chemical weathering reactions, which produce clay minerals and nutrient-rich soil waters (Fig. 1). Plant roots absorb nutrients from soil waters, which continue to be charged with nutrients until weathering advances sufficiently for soil waters to lose contact with primary rock and nutrient rich clay minerals. Intensely weathered soils are infertile and are characterised by mineral phases composed principally of oxides of silicon, aluminum and iron.

Most tropical forests, such as those of the lower Amazon Basin, overlie highly infertile soils (KRONBERG et al., 1979). To accommodate the scarcity of nutrients the forests have evolved mechanisms for nutrient retention and recycling, by which nutrient flows are closed within the biomass 


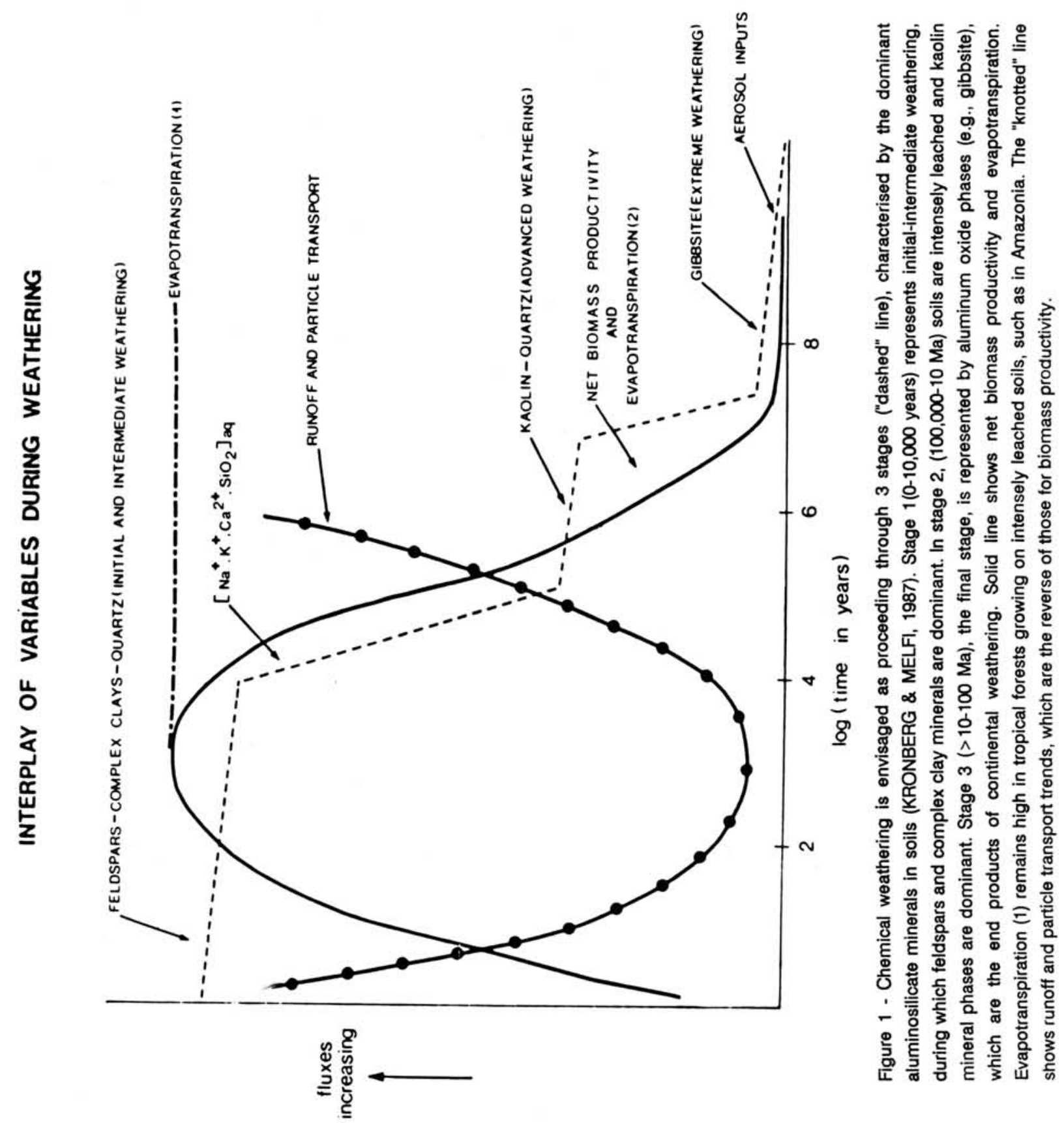


(JORDAN, 1985). Small losses to ground waters are replenished by nutrient additions from rains and aerosols. The tenuous status of rainforest nutrients reserves has profound consequences for the use of these terranes for large scale agroforestry. Small scale agroforestry has sustained inhabitants of lowland tropical regions for centuries (NYE \& GREENLAND, 1960). The difference in scales is crucial. In small clearings used for "shifting" cultivation, nutrients supplied by biological debris remaining after forest burning and clearing are sufficient for a few harvests. These small disruptions to local ecosystems are repaired naturally after several years of fallow. However, in large scale agroforestry ecosystem disruptions are naturally irreparable. Sustainable agriculture is also practiced successfully in Amazonia on extensive river floodplains, where soils are renewed each year by the deposition of nutrient-rich sediments from Andean regions.

In boreal forests, nutrient dynamics are also complex (BRUENIG, 1987). The colder soil temperatures depress microbial activity and nutrient flow rates relative to those in tropical forest ecosystems. This factor presumably contributes to nitrogen being considered the most limiting nutrient in boreal ecosystems, unlike in tropical forests, where high levels of microbial activity ensure an ample supply of fixed nitrogen. In general, inorganic nutrient availabilty is not a prevalent problem, in northern temperate and boreal forest ecosystems due to the geologically recent intense glacial activity, which left vast quantities of rock debris strewn over land surfaces. In a global weathering model (Fig. 1), glacial soils represent the initial and intermediate stages of weathering and are much younger ( 10,000 years) than those in lowlying tropical region which have been undergoing weathering for millions of years. The young soils of boreal regions are mineralogically complex and contain high proportion of primary and complex clay minerals (feldspar, smectite, illite, chlorite, etc.). However, peatland soils, which are common in boreal regions, tend to have low levels of inorganic nutrients due to the acidity of peat drainage waters, which easily leach nutrient cations.

\section{PREDICTING CONSEQUENCES OF LARGE-SCALE PERTURBATIONS TO TROPICAL AND BOREAL FORESTS}

Modelling the potential effects of deforestation is limited by our fragmentary knowledge of natural biogeodynamical interactions in forests as well as of quantitative information on the rate and extent of deforestation (HENDERSON-SELERS et al., 1988). Widespread deforestation sets in motion a chain of events. For example, in tropical forests where significant amounts of rain are recycled, forest clearing immediately increases surface runoff. The excess waters are diverted to rivers and oceans and permanently lost to the system. Concomitantly, there are reduced rates of evapotranspiration and soil recharge and precipitation. This results in diminishing water fluxes to the atmosphere and less cloud 
formation. The overall effect is an increase in solar radiation and less total water in the system.

Climate change predictions for the middle to high latitudes of the northern hemisphere agree on a warming of several degrees Celsius over the next one to three decades. These temperature changes coupled with the increases in atmospheric carbon dioxide contents could, at first glance, be assumed to enhance tree growth rates in the northern temperate and boreal forests. Further analysis illustrates the complexity of the interactions of factors affecting biotic processes in forests. Rates of photosynthesis and respiration are affected by the availability of energy, water, inorganic nutrients and changes in temperature (the effect of atmospheric carbon dioxide concentration is small by comparison). From limited ecosystem estudies, it appears that in forest the process most sensitive to temperature change is respiration. The indications are that a strong warming effect in the northern temperate and boreal latitudes could lead to respiration rates which outstrip those for carbon fixation (WOODWEL, 1987). Also clearing forest raises the temperature of the forest floor leading to enhanced microbial respiration. Even the creation of high frequency wetting-drying cycles, caused by canopy removal, may accelerate decomposition. An especially important consideration for the boreal region is the accelerated decomposition of organic matter as peatlands are drained and deforested (REINERS, 1975). These considerations for the boreal region suggest that deforestation of boreal forests has a greater effect on continental carbon dioxide fluxes to the atmosphere than do the clearing of tropical forests.

Other studies (PASTOR \& POST, 1988) indicate that climate change could affect forest carbon and nitrogen cycles and species distributions. The greatest changes are predicted at the current boreal/northern temperate forest border. Their results point out that "Forest responses to climate change are as sensitve to the indirect effects of climate and vegetation on soil properties as they are to direct effects of temperature on tree growth". WOODWELL (1987) also draws attention to consequences of climate changes at the deciduous/conifer transition zone. Most important is that the rate of northward migration of coniferous forests in response to climate warming would not be matched by the much slower rate of migration of deciduous forests.

From a global perspective there is no doubt that the terrestrial biomass is being reduced and the greatest reductions are those involving forests (WHITTAKER \& LKENS, 1975). The chief reduction process is the replacement of older forests with younger growth. Forest carbon contents are further reduced by decay of soil organic matter following clearing. It is difficult to imagine changes in the biosphere which will reverse the changes underway in the forest and atmosphere carbon pools. Clearly, our knowledge of carbon dynamics in terrestrial ecosystems is inadequate for ensuring that continuing present deforestation rates will not be calamitous.

\section{REFERENCES}


BROWN, S. \& LUGO, A.E. (1982) The storage and production of organic matter in tropical forests and their role in the global carbon cycle. Biotropica, 14:161-187.

BROWN, L.R. \& WOLF, E.C. (1984) Soil erosion: quiet crisis in the world economy. Worldwatch Paper, 60:1-49.

BRUENIG, E.F. (1987) The forest ecosystem: tropical and boreal. Ambio, 16(2-3):68-79.

D'ARRIGO, R.; JACOBY, G.C.; FUNG, I.Y. (1987) Boreal forests and atmosphere-biosphere exchange of carbon dioxide. Nature, 329:321-323.

FYFE, W.S.; KRONBERG, B.I.; LEONARDOS, O.H.; OLORUNFEMI, B.N. (1983) Global tectonics and agriculture: a geochemical perspective. Agriculture, Ecosystems and Environment, 9:383-399.

HENDERSON SELLERS, A.; DICKINSON, R.F.; WILSON, M.F. (1988) Tropical deforestation: important processes for climate models. Climatic Change, 13:43-67.

HOUGHTON, R.A. \& WOODWEL, G.M. (1989) Global climate change. Scientific American, 260(4):36-44.

JORDAN, C.F. (1985) Nutrient cycling in tropical forest ecosystems. New York, John Wiley and Sons. $190 \mathrm{p}$.

KRONBERG, B.I.; FYFE, W.S.; LEONARDOS, O.H.; SANTOS, A.M. (1979) The chemistry of some Brasilian soils: element mobility during intense weathering. Chemical Geology, 24(3/4):211-229.

KRONBERG, B.I. \& MELFI, A.J. (1987) The geochemical evolution of lateritic terranes. Zeitschrift für Geomorphologie, 64:25-32.

MERTZ, W. (1981) The essential trace elements. Science, 213:1332-1338.

MOLION, L.C.B. \& BETANCURT, J.J.U. (1981) Land use and agrosystem management in humid tropics. In: TABOLT, J.J. \& SWANSON, W. (eds.) Woodpower: new perspectives on forest usage. Oxford, Pergamon. p.119-128.

MOORE, B. \& BOLIN, B. (1987) The oceans, carbon dioxide and global climate change. Oceanus, 29(4):915. 
NEWELL, R.C. (1971) The Amazonas forest and the atmospheric general circulation. In: KELLOGG, W.H. \& ROBINSON, G.D. (eds.) Man's impact on the climate. Cambridge, MIT Press. p.457-459.

NYE, P.H. \& GREENLAND, D.J. (1960) The soil under shifting cultivation. Commonwealth Bureau of Soils. Harpenden, England. 156p.

PASTOR, J. \& POST, W.M. (1988) Response of northern forests to $\mathrm{CO}_{2}$ - induced climate change. Nature, 334:55-57.

PERSSON, T. (1980) Structure and function of northern coniferous forests. Swedish Ecological Bulletin 32. Swedish Natural Science Research Council, 609p.

REICHLE, D.E.; DINGER, B.E.; EDWARDS, N.T.; HARRIS, W.F.; SOUUNS, P. (1975) Carbon flow and storage in a forest ecosystem. In: Carbon and the Biosphere, U.S.A.E.C. Symposium Series 30, p.281302.

REINERS, W.A. (1975) Terrestrial detritus and the carbon cycle. In: Carbon and the Biosphere, U.S.A.E.C. Symposium, p.303-327.

SALATI, E. \& VOSE, P.B. (1984) Amazon Basin: a system in equilibrium. Science, 225:129-138.

TARNOCAI, C. (1972) Some characteristics of cryic organic soils in northern Manitoba. Canadian Journal of Soil Science, 52:485-496.

WHITTAKER, R.H. \& UKENS, G.E. (1975) Carbon in the biota. In: Carbon and the Biosphere, U.S.A.E.C. Symposium, Series 30, p.281-302.

WOODWELL, G.M. (1972) Forests and climate: surprises in store. Oceanus, 29(4):71-75. 